\title{
Early Auditory Experience and the Ontogeny of Alarm-Call Discrimination in Belding's Ground Squirrels (Spermophilus beldingi)
}

\author{
Jill M. Mateo \\ University of Michigan, Ann Arbor
}

\begin{abstract}
Because young ground squirrels are vulnerable to predation, selection would favor the early ability to respond to alarm calls. This requires discrimination of classes of alarm calls from each other as well as from non-alarm calls. Pre-emergent auditory experience may influence the development of discrimination. As a means of determining when Belding's ground squirrels (Spermophilus beldingi) can discriminate among calls, cardiac responses to alarm calls and control stimuli were recorded from 2 rearing groups that differed in the frequency of alarm-call exposure. Results suggest that before natal emergence, young can discriminate between 2 classes of alarm calls but they may not discriminate these calls from control stimuli. No differences in responses were found between the rearing groups; thus experience with calls may not influence the onset of discrimination. Early discrimination may facilitate the rapid development of post-emergent behavioral alarm-call responses.
\end{abstract}

In many species of group-living birds and mammals, the appearance of a predator elicits vocalizations that can alert other animals of impending danger (for a review, see Klump \& Shalter, 1984). These alarm calls may be especially important to individuals that have not already detected the predator, because the calls indicate that danger is imminent and quick action is required to reduce the likelihood of capture. Responding properly to alarm calls may be especially important to immature young, because they are generally more susceptible to predators than adults. Given that trial-and-error learning can be fatal, one might expect that inexperienced young would be able to respond appropriately to alarm calls the first time they heard such calls. This expectation raises the question of when and how young develop adaptive behavioral responses to alarm calls. To display such responses, young must first be able to discrim-

Jill M. Mateo, Department of Psychology, University of Michigan, Ann Arbor.

This article is based on research conducted by Jill M. Mateo in partial fulfillment of the requirements for the $\mathrm{PhD}$ degree in psychology at the University of Michigan. The research was supported by a National Science Foundation Dissertation Improvement Grant and a University of Michigan Office of the Vice President for Research grant.

I thank Megan Clancy and Jennifer Osborn for their assistance in caring for the animals and collecting the data discussed herein. I especially thank Warren Holmes for his support in all aspects of my research and for making the equipment and facilities available to me. I also thank Dan Dawson, manager of the field station, for facilitating and encouraging my research. J. Alberts and A. Ronca offered useful suggestions for the collection of cardiac data from young rodents. E. Rothman and K. Welch of the University of Michigan's Center for Statistical Consultation and Research provided invaluable statistical assistance: Finally, this article benefited greatly from comments by W. Ȟ Owings, and A. Ronca.

Correspondence concerning this article should be addressed to Jill M. Mateo, who is now at Department of Psychology, Uris Hall, Cornell University, Ithaca, New York 14853. inate alarm calls from other auditory stimuli, and then they must develop appropriate responses to the different stimuli they detect. In this article, I focus on the ontogeny of discrimination; elsewhere, I have addressed the ontogeny of behavioral responses (Mateo, in press).

Belding's ground squirrels (Spermophilus beldingi) are one of several species of group-living, ground-dwelling sciurids (marmots [Marmota], prairie dogs [Cynomys], and ground squirrels) that emit alarm calls when they detect aerial and terrestrial predators (Robinson, 1980, 1981; Sherman, 1985). Like all members of their genus, S. beldingi young develop for the first few weeks of their lives in underground burrows (natal burrows), to which only their dam has access, and they do not begin to hear alarm calls routinely until they first come above ground at about 25 days of age (their natal emergence; Sherman, 1976). However, $S$. beldingi dams sometimes vocalize as they enter their natal-burrow tunnels (e.g., if they are being chased by a predator), and they may vocalize and respond behaviorally to auditory stimuli they detect while they are below ground with their pups. The auditory experience that pups have in the relative safety of their natal burrow may influence how they respond to the challenges posed by the radically new environment they encounter at natal emergence. Variation in early auditory experience can accelerate or delay maturation of aurally mediated behaviors in duck (Anas platyrhynchos) embryos (Gottleib, 1971) and rat pups (Rattus norvegicus; Alberts, 1984). Similarly, differences in preemergent rearing histories affect how post-emergent $S$. beldingi juveniles respond to alarm-call playbacks (Mateo, 1995). Exposure to conspecific alarm calls while in the natal burrow, then, may influence the development of auditory discrimination by young ground squirrels. Hence, the purpose of my study was to determine whether the preemergent auditory experience of $S$. belding $i$ pups, especially vocalizations by dams, affect pups' abilities to differentiate among conspecific calls.

$S$. belding $i$ emit two acoustically distinct alarm calls, trills 
and whistles, in addition to a variety of other vocalizations (Leger, Berney-Key, \& Sherman, 1984). Trills are composed of a series of five or more short, high-frequency notes (Figure 1) and are elicited primarily by terrestrial predators or other predators that pose no immediate threat. On hearing trills, adult $S$. beldingi often post (a bipedal stance accompanied by visual scanning). In contrast, whistles usually cause ground squirrels to scramble to the nearest burrow, often going below ground. These single, high-frequency calls are usually elicited by aerial predators or other predators that pose an immediate threat (Robinson, 1980, 1981; Sherman, 1985).

Because young-of-the-year that have undergone natal emergence (juveniles) are particularly susceptible to predation (Sherman \& Morton, 1984) and because alarm calls can warn them of attacks, juveniles should respond correctly to the two alarm calls shortly after natal emergence, which requires discrimination of the vocalizations. (I use the term discrimination to indicate differential physiological or be-

(a)

$\mathrm{kHz}$

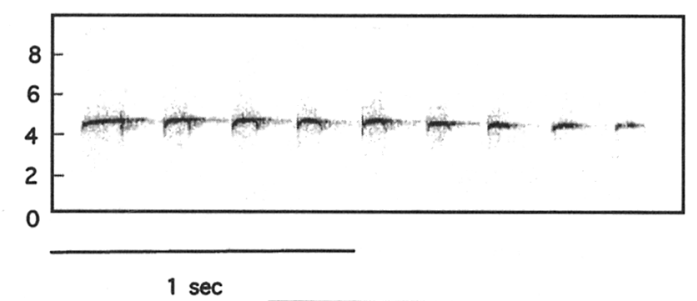

(b)

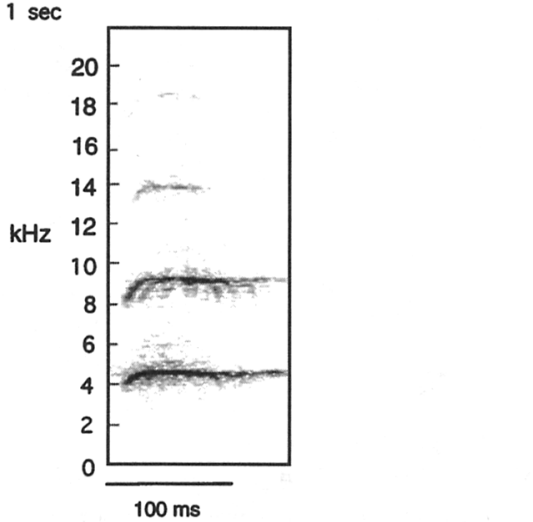

(c)

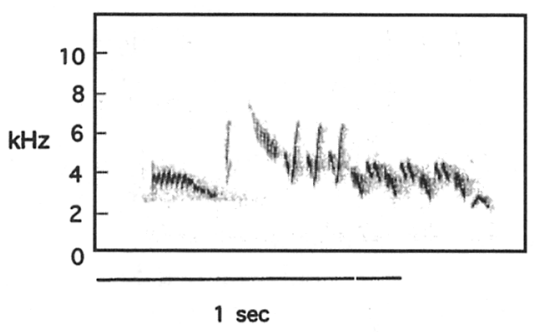

Figure 1. Representative spectrograms of playback stimuli. Frequency is scaled in $2-\mathrm{kHz}$ increments, and time is indicated below each spectrogram: (a) free-living adult female $(>1$ year old) $S$. beldingi trill in response to an approaching human; (b) free-living adult female $S$. belding $i$ whistle in response to an aerial predator; (c) house wren song (unknown sex or age). havioral responses to classes of auditory stimuli. Discrimination can therefore imply "recognition" of classes of stimuli as biologically salient but does not infer the "meaning" of the stimuli.) Thus, discriminative responses to whistles and trills may increase a juvenile's chances of escaping from aerial and terrestrial predators, whereas disregarding a nonalarm call would allow a juvenile to continue foraging, pre-hibernation body fat being critical to over-winter survival (Murie \& Boag, 1984). The ability of naive ground squirrels to respond to alarm calls in an age-appropriate manner may result from auditory experience prior to natal emergence, from hearing and responding to alarm calls and from observing conspecifics' response to calls after natal emergence, or both. Here I am interested in the development of auditory discrimination, which must precede the development of behavioral responses; therefore, I specifically address the influence of pre-emergent auditory experience on the ontogeny of discrimination.

Using alarm-call playbacks, I have found that newly emergent juveniles do not respond in a reliable, observable manner to calls indicating predation threats. Young juveniles are just as likely to respond (or not respond) to alarm calls as they are to respond to other conspecific vocalizations or even bird vocalizations. When they do respond, they typically freeze rather than run to a nearby, and safe, burrow (Mateo, in press). Evidence of auditory discrimination by newly emergent juveniles may have been masked by their limited motor skills. Observable measures of discrimination by animals with finite behavioral repertoires can be obtained by examining the cardiac responses elicited by various stimuli (Berntson, Boysen, Bauer, \& Torello, 1989; Dooling \& Searcy, 1980; Martin \& Alberts, 1982). I therefore used heart-rate measures to determine when $S$. beldingi can discriminate between two conspecific alarm calls and between alarm calls and a heterospecific auditory stimulus, as well as how pre-emergent auditory experience affects this discrimination.

In this article, I use standard terms from the field of cardiac psychophysics (for reviews, see Berntson, Boysen, \& Cacioppo, 1992; Martin \& Alberts, 1982; Richardson, Hayne, \& Campbell, 1992). Acceleratory cardiac responses, such as defensive reactions and startle reactions, are typically elicited by intense or potentially injurious stimuli and may be coupled with involuntary behavioral activity. Therefore, tachycardia, or increased heart rate, is generally associated with aversive stimuli, resulting in decreased sensory processing and filtering of extraneous stimuli. In contrast, orienting responses are cardiac decelerations to novel, innocuous stimuli that are often accompanied by somatic inhibition. Thus, orienting responses are associated with approachable (or neutral) stimuli and enhance the reception of environmental stimulation so as to increase perceptual and attentional focusing. The nature of the cardiac response can be used to infer how developing $S$. beldingi perceive alarm calls. For example, an alarm call may evoke a decreased heart rate (bradycardia) if a ground squirrel detects the call and attends to it or tachycardia if the animal is startled by the call or perceives it as a threat. However, threatening stimuli (e.g., alarm signals or approaching vi- 
sual stimuli) may also result in bradycardia (Berntson et al., 1989; Espmark \& Langvatn, 1979; Gabrielsen, Blix, \& Ursin, 1985; Jacobsen, 1979; Ruff, 1971; Smith \& Woodruff, 1980).

Cardiac responses are especially useful for studying the salience of species-typical stimuli to very young animals. Heart-rate responses can reveal both the detection (Espmark \& Langvatn, 1979; Gabrielsen et al., 1985; Jacobsen, 1979) and discrimination (Berntson \& Boysen, 1989; Martin \& Alberts, 1982) of biologically important stimuli by young animals that are incapable of motoric responses. For instance, in a classic article on perceptual learning, Dooling and Searcy (1980) used cardiac responses to examine song preferences in young sparrows. Nestling swamp sparrows (Melospiza georgiana) discriminated conspecific from heterospecific songs, whereas song sparrow (M. melodia) heart rates did not differentiate between song types. These species differences in cardiac responses paralleled later selectivity in song learning.

The purpose of my study was to determine whether preemergent and post-emergent $S$. beldingi can discriminate between conspecific trills and whistles and between these alarm calls and heterospecific vocalizations (wren songs). In addition, I examined how differential experience with conspecific alarm calls affects the development of discriminative abilities (Impekoven, 1976; Lickliter \& Stoumbos, 1991; Rydén, 1978; Vince, 1980). I compared the heart-rate responses of animals exposed to extensive pre-emergent auditory stimuli with the responses of young without such experience. My purpose was to determine at what age, if any, the effects of early auditory experience become manifest (i.e., when the heart-rate-response patterns of young from the two rearing conditions begin to diverge). To raise pups without exposure to conspecific calls, I attempted to mute six dams with bilateral lesions of the inferior laryngeal nerve (after Thomas, Talalas, \& Barfield, 1981) but was unsuccessful in completely eliminating their production of alarm calls. Therefore, to study pups that differed in auditory experience with calls, I created two groups: One was exposed to frequent alarm calls (loud group), and another experienced a less frequent, more species-typical rate of calls (quiet group).

\section{Method}

\section{Study Site and Animals}

Research was conducted during the summer of 1993 at the Sierra Nevada Aquatic Research Laboratory (SNARL), near Mammoth Lakes, California, in the east-central Sierra Nevada. Fieldmated females were live trapped from populations near Saddle Bag Lake in Mono County, California (3,000-3,400 m elevation). Young were born and reared in a laboratory at SNARL; each dam and litter were housed in a plywood nest box $(28 \times 20 \times 20 \mathrm{~cm})$ fitted with a 6-cm-diameter entry hole and a removable top. Each nest box contained wood shavings and was located inside a stainless steel cage $(61 \times 45 \times 35 \mathrm{~cm})$. The laboratory was maintained on a 13:11-hr light-dark schedule; the temperature was regulated by a combination of a heater and automatic fans. Purina mouse chow (\#5015) and water were provided ad libitum, and small amounts of vegetables (carrots and lettuce) and sunflower seeds were occasionally provided. Pups were sexed the day after birth and individually marked (unique combinations of the distal 0.5 $\mathrm{mm}$ of toenail buds were removed).

\section{Procedure}

I measured each animal's heart-rate response to playbacks of recorded calls four to five times between the ages of 13 and 49 days. Behavioral responses in the field begin within a few days of natal emergence and resemble adult responses by 50 days of age (Mateo, in press). For developmental analyses, I grouped ground squirrels into two pre-emergent (13-19 days and 20-24 days) and two post-emergent (30-39 days and 40-49 days) age cohorts. No playbacks were conducted between the ages of 25 and 29 days because this range includes the typical time of natal emergence (Sherman, 1976; mean weight $\pm S E M=46.39 \mathrm{~g} \pm 1.38 ; n=35$ ). It is unclear, then, whether captive individuals in this age range would be considered pre-emergent or post-emergent young, which prevented interpretation of their cardiac data in an ecological framework. In rats (Rattus norvegicus), the onset of functioning of the auditory system precedes cardiac responses to stimuli (Alberts, 1984; Haroutunian \& Campbell, 1981). In addition, startle responses to loud noises are not observed in $S$. beldingi pups until about 15-18 days, a few days after their ears open (personal observation). Therefore, I began testing at 13 days of age, rather than the day of birth, because pups would not have responded to auditory stimuli before this age and because I was interested in the experiential factors that may have influenced the development of discrimination. Finally, I found similar results when I analyzed the post-emergent data by smaller cohorts; thus, data were pooled into 10-day cohorts.

I arbitrarily assigned pups and their dams to one of two rearing conditions. Animals in the loud group ( $n=19$ pups from four litters [ 9 females and 10 males]) were reared in the laboratory, which housed an additional 20 dams and their young. Because dams and older pups often vocalize in the laboratory, another rearing condition was created to limit the amount of auditory stimulation experienced by developing pups to a more speciestypical level. Thus a quiet group of three litters $(n=15$ pups $[10$ females and 5 males]) was housed in a separate building. Space limitations prevented the formation of a third group, such as one composed of a single litter. To estimate the magnitude of auditory stimulation experienced by pups reared in the two settings, observers opportunistically recorded the number of vocalizations (chirps, trills, and whistles; Leger et al., 1984) heard during 1-hr samples. Dams and older juveniles in the loud group emitted (mean $\pm S E M) 13.3 \pm 4.37$ calls per hour; the quiet group produced only $5.2 \pm 2.47$ calls per hour.

\section{Playback Stimuli}

I used three classes of auditory stimuli: trills and whistles, the two $S$. beldingi alarm calls, and house wren (Troglodytes aeodon) songs (Figure 1). House wrens are oscines sympatric with $S$. belding $i$, and their songs are not associated with predatory contexts. These three vocalizations enabled me to determine when $S$. beldingi begin to respond differentially to threatening (trills and whistles) and nonthreatening (bird calls) stimuli. All calls were recorded in the field in 1991 with a Sony TC-D5M Pro Stereo cassette recorder and Realistic omnidirectional microphone. Stimuli were naturally elicited (wren songs and some trills) or evoked by flying a frisbee over a colony or by slowly approaching the 
ground squirrels (whistles and some trills). Stimuli were band-pass filtered (300 to $16000 \mathrm{~Hz}$ ) and then digitized with Signal Software (Engineering Design, 1992). Recordings were played back on a Sony TC-D5M tape recorder connected to a Nagra DH amplifierspeaker positioned $2 \mathrm{~m}$ from the animal. All stimuli were played at peak amplitudes approximating natural intensities (whistle $=88$ $\mathrm{dB}$, trill $=75 \mathrm{~dB}$, and wren song $=60 \mathrm{~dB}$, measured with a Realistic sound level meter on A weighting). The whistle exemplars were a mean $( \pm S E M)$ of $0.10 \mathrm{~s} \pm 0.01$ in duration, whereas the trills were $1.95 \mathrm{~s} \pm 0.17$ in duration and the wren songs were $1.34 \mathrm{~s} \pm 0.08$ in duration. Because $I$ was interested in whether newly emergent juveniles could discriminate among natural calls the first time they were heard in the field, and because a predator may elicit only one alarm call (Sherman, 1976, 1985), stimuli were presented once at their natural durations rather than at equal durations (Gerhardt, 1992). Therefore, the stimulus characteristics that free-living animals may use to distinguish among the calls (duration, frequency range, amplitude, and number of syllables) were also available to the animals studied here. Eight exemplars of each stimulus were used in the playbacks and were presented in a balanced order (Kroodsma, 1986).

\section{Bioassay for Ground Squirrels' Responses to Playbacks}

Animals were separated from their dam and siblings and transported to a quiet room in a separate building. They were tested alone in their familiar nest box with the top closed, creating a quiet and dark testing environment; tests began after a 5-min acclimatization period during which no auditory stimuli were presented. Heart rates were monitored for approximately $30 \mathrm{~s}$ before and 30 $s$ after stimulus presentation. To record an animal's cardiac response to an auditory stimulus, I temporarily fitted each ground squirrel with two subcutaneous copper-wire electrodes. I inserted one electrode ventrally near the navel region and placed the other dorsally at the nape of the neck. Each wire was stripped of $1 \mathrm{~cm}$

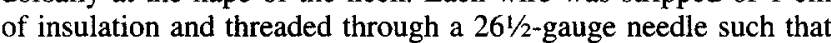
a $0.5-\mathrm{cm}$ section extended from the needle tip and was bent back. I inserted the needle subcutaneously and then withdrew it slowly, with the wire loop remaining under the skin. Because of the effect of inhalant anesthetics on heart rates (Gilman, Rall, Nies, \& Taylor, 1990), animals were not anesthetized during needle insertion. After the initial needle prick, animals did not appear to be distressed by the electrodes. Animals were loosely wrapped with an ace bandage to prevent them from moving about and thereby removing electrodes.

Cardiac signals (electrical activity, in volts, associated with heart-muscle contractions) were transmitted to a BIOPAC workstation (Goleta, CA) composed of an MP100 data acquisition unit, an ECG100A electrocardiogram amplifier, and a portable computer. Each "record" (the total prestimulus and poststimulus cardiac output during one playback presentation for 1 animal) was stored directly on the computer. For each playback session, a ground squirrel was presented with one exemplar of each of the three playback stimuli (approximately one every $5 \mathrm{~min}$, allowing heart rates to return to baseline between playbacks), thus producing three records for that session. The order of playback presentations was balanced across animals.

\section{Data Analysis}

To quantify ground squirrels' responses to auditory stimuli, I first conducted second-order autoregressions, which allowed me to compute $S$, beldingi cardiac rates (in beats per minute [BPM]). Each record of an animal's cardiac response to a playback was divided into a prestimulus period and a poststimulus time period that were analyzed separately. I restricted the intervals to $5 \mathrm{~s}$ prestimulus and $5 \mathrm{~s}$ poststimulus because shorter intervals were too brief to capture a full response and lengthening the interval did not reveal changes in heart rate that were not detected with 5-s intervals. A visual inspection of the voltage spectrum indicated no large changes in heart rate from second to second; therefore, all data from a 5-s interval were pooled for analyses.

A second-order autoregression (Model ARIMA, lag $=2$, SAS System for Windows 3.10; SAS Institute, Cary, NC) was performed on the raw voltage data for both the prestimulus and poststimulus periods (150 samples per second for $5 \mathrm{~s}$ each) from each record. In short, this analysis regressed each sample data point against itself. The model assumed that any point of the voltage spectrum, $y_{t}$, can be determined by the two preceding points in time (Lags 1 and 2) and by noise, represented in the following formulation:

$$
y_{t}^{\prime}=\phi_{1} y_{t-1}+\phi_{2} y_{t-2}+e,
$$

where $\phi_{1}$ denotes the first autoregressive parameter estimate from Lag 1 at time $t-1, \phi_{2}$ denotes the second autoregressive parameter at time $t-2$, and $e$ denotes a white-noise process. Autocorrelations beyond the second lag were not significant and thus were not included in the model.

Next, I used these parameter estimates to calculate the modal heart-rate frequency $\left(F_{o}\right)$ for each prestimulus and poststimulus time period (after Jenkins \& Watts, 1968) using the following formula:

$$
F_{o}=\frac{1}{2 \pi \Delta} \cos ^{-1}\left[\frac{-\phi_{1}\left(1-\phi_{2}\right)}{4 \phi_{2}}\right],
$$

where $\Delta$ denotes the sampling interval. Modal frequency was used rather than estimates of the mean because of the large variation in the analog data and because of erratic samples due to line noise and extraneous stimuli. Finally, each modal frequency was multiplied by 60 to generate BPM.

A "response score" was calculated for each animal's cardiac response to a playback stimulus. This score was expressed as the percentage change in BPM from the prestimulus period to the poststimulus period; $0 \%$ indicates no change in heart rate, a negative percentage represents bradycardia, and a positive percentage represents tachycardia. Response scores were normally distributed and therefore did not require transformation. Homogeneity of heart rates before the playbacks was tested with one-way analyses of variance (ANOVAs) for each age-cohort-rearing-condition combination. I examined sex and litter differences in response scores to each stimulus with two-way ANOVAs (Sex or Litter $\times$ Playback Stimulus) within each age cohort. Next, I conducted a three-way ANOVA (Rearing Condition $\times$ Playback Stimulus $\times$ Age Cohort) on response scores to examine the effects of early auditory experience and development on heart-rate responses to the three auditory stimuli. Because of large variation in the magnitude of responses, I also conducted McNemar change tests on the direction of response scores to the three playback stimuli (increase or decrease; details are provided in a later section). A repeated measures analysis was inappropriate because not all animals were tested in all age cohorts (as a result of time constraints) and because of missing data (as a result of poor heart-rate recordings). Significant differences in the magnitude of response scores or the direction of responses to each stimulus would indicate discrimination of the stimuli (Berntson et al., 1992; Dooling \& Searcy, 
1980; Martin \& Alberts, 1982). Data are presented as means ( \pm $S E M)$. For all analyses, the significance level was set at $p<.05$.

The BIOPAC system had not previously been used to record sciurid heart rates. To ensure that the equipment was capable of recording the fast heart rates of $S$. belding $i$ and of measuring cardiac responses, I first tested a separate group of pups with a range of audiotactile stimuli certain to evoke a physiological response. These stimuli included blowing on the muzzle of the animal, shaking the nest box vigorously, banging a table on which the nest box was placed, and suddenly pushing the animal with a finger. I presented the test stimuli to 5 pups (approximately 16 days of age, with ears open). Because of small sample sizes for the various test stimuli, all data were pooled. A dependent $t$ test conducted on the response scores revealed significant changes in heart rates. Pups exhibited marked bradycardia $(M=-5.40 \% \pm$ 3.34 BPM) after the audiotactile stimuli, $t(27)=2.36, p<.05$. These results confirmed that the BIOPAC system was sensitive enough to detect and record changes in $S$. belding $i$ heart rates.

\section{Results}

\section{Baseline BPM}

Prestimulus BPM served as baseline BPM for each ground squirrel for each playback. The baseline BPM values of all animals for all stimuli were averaged within each rearing condition and age cohort. Mean baselines increased significantly with age, $F(3,345)=53.41, p<.001$, but also differed between rearing conditions within each cohort. Between 13 and 39 days of age, animals housed in the quiet environment had significantly lower baseline heart rates than those reared in the loud environment (independent $t$ tests for each age cohort). After 40 days, however, no significant difference in baseline BPM was observed (Figure 2).

I conducted one-way ANOVAs on baseline BPM with playback stimulus as the independent variable to determine whether heart rates differed before the onset of each stim-

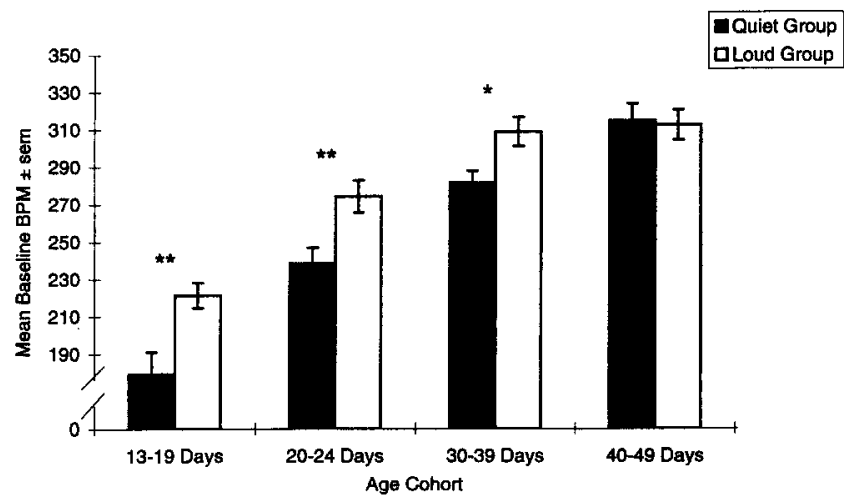

Figure 2. Mean ( $\pm S E M$ ) baseline heart rate (beats per minute [BPM]) during 5-s prestimulus period for the quiet and loud rearing conditions. Asterisks represent significant $\left({ }^{*} p<.05\right.$, $* * p<.01)$ between-groups differences as revealed by independent $t$ tests (see text for explanation of age cohorts and Table 1 for sample sizes). ulus. No significant differences were found within any of the age-cohort-rearing-condition combinations.

\section{Detection of Auditory Stimuli}

The variation in response scores between litters did not exceed the variation within litters; thus, the responses of individuals within a litter were considered independent. In addition, there were no sex differences in response scores within any age cohort; the sexes were therefore grouped for all subsequent analyses.

The playback stimuli evoked bradycardia in young $S$. beldingi, with the poststimulus rate of all ground squirrels for all stimuli decreasing by an average of $2.96 \% \pm 0.51$ relative to the prestimulus period (see Table 1 for a detailed summary). This small but consistent decrease in heart rate was typical of orienting responses and confirmed that the animals heard the playback stimuli. The relatively small magnitude of the mean decreases, however, may have been due to a large interindividual variation in responses, including instances of tachycardia. For example, during the last cohort the wren song stimulus evoked a pronounced decrease in heart rate in a loud-group juvenile $(-36.40 \%)$, whereas it elicited marked tachycardia $(+15.39 \%)$ in a quiet-group individual. Indeed, the proportions of young exhibiting bradycardia (a response score of less than $0 \%$ ) were $59.7 \%$ for whistles, $63.1 \%$ for trills, and $62.9 \%$ for wren songs when data from the four age cohorts were combined (Figure 3). Categorical analyses for each playback stimulus revealed that significantly more ground squirrels exhibited cardiac deceleration to the whistle stimulus at 40 to 49 days of age than at 13-19 days, Yates's $\chi^{2}(1)=$ $4.08, p<.05$. It is possible that the youngest pups did not detect the whistle stimulus because of its short duration $(\sim 100 \mathrm{~ms})$. Considering only those animals that displayed bradycardia, the average change in heart rate from baseline was significant $(M \pm S E M=-6.82 \% \pm 0.49 \%)$, paired $t$ $(213)=12.54, p<.001$.

\section{Effects of Early Auditory Experience and Age on Responses to Playback Stimuli}

The three-way ANOVA yielded no significant main effects or interactions (all $p s>.05$ ) when response scores were analyzed by rearing condition, playback stimulus, and age cohort. Thus, on the basis of the magnitude of prestimulus to poststimulus change in BPM, ground squirrels in both the quiet and loud groups failed to respond differentially to the three playback stimuli at any age. However, because of the large interindividual variation in the magnitude of cardiac responses (see Table 1), I also examined the direction of heart-rate change, that is, whether individuals exhibited distinct bradycardia or tachycardia after presentation of each of the three playback stimuli. To ensure that very small heart-rate changes did not bias the sample, I limited this data set to responses that were more or less than 0.5 standard deviation from the mean response score in that playbackstimulus-age-cohort combination. Because no differences 
Table 1

Mean Percentage Change in Beats per Minute ( \pm SEM) From Prestimulus to Poststimulus Period

\begin{tabular}{|c|c|c|c|c|}
\hline \multirow{2}{*}{$\begin{array}{l}\text { Rearing condition } \\
\text { and stimulus }\end{array}$} & \multicolumn{4}{|c|}{ Age cohort } \\
\hline & 13-19 days ${ }^{a}$ & $20-24$ days $^{b}$ & $30-39$ days $^{c}$ & $40-49$ days $^{\text {d }}$ \\
\hline \multicolumn{5}{|l|}{ Quiet group } \\
\hline Whistle alarm call & $-2.53 \pm 1.98$ & $-4.58 \pm 1.62$ & $-1.62 \pm 1.28$ & $-4.33 \pm 1.25$ \\
\hline Trill alarm call & $-7.27 \pm 5.32$ & $-2.95 \pm 2.12$ & $+0.11 \pm 1.68$ & $-1.75 \pm 1.83$ \\
\hline Wren song & $-0.21 \pm 4.39$ & $-3.06 \pm 1.89$ & $-5.43 \pm 2.51$ & $+0.62 \pm 0.93$ \\
\hline \multicolumn{5}{|l|}{ Loud group } \\
\hline Whistle alarm call & $-2.97 \pm 2.46$ & $-6.90 \pm 3.18$ & $-3.36 \pm 1.83$ & $-0.63 \pm 2.93$ \\
\hline Trill alarm call & $+0.12 \pm 3.36$ & $-5.89 \pm 3.62$ & $-3.33 \pm 2.50$ & $-3.46 \pm 1.71$ \\
\hline Wren song & $-1.41 \pm 1.13$ & $-3.21 \pm 2.22$ & $-2.09 \pm 2.20$ & $-8.25 \pm 4.15$ \\
\hline
\end{tabular}

were found between rearing conditions, I pooled the quiet and loud groups within each age cohort.

The proportions of ground squirrels clearly responding with either bradycardia or tachycardia to the auditory stimuli suggest that in all but the 13-19-day-old pups, whistles elicited decreased heart rates more often than trills (Figure 4). I conducted McNemar change tests (Siegel \& Castellan, 1988) to determine whether individual animals that exhibited bradycardia to whistles were also likely to respond with tachycardia to trills. No discrimination between auditory stimuli was evident in young pups 13-19 days of age. However, by 20-24 days, responses to the two stimuli began to differentiate. Significantly more pups responded with decreased heart rates to the whistle stimulus and increased rates to the trill in comparison with chance (onetailed binomial probability, $p<.05$ ). This pattern approached significance in the two older cohorts $(p=.09$ for both 30-39 and 40-49 days of age). At 40-49 days of age, more juveniles responded with bradycardia to whistles and

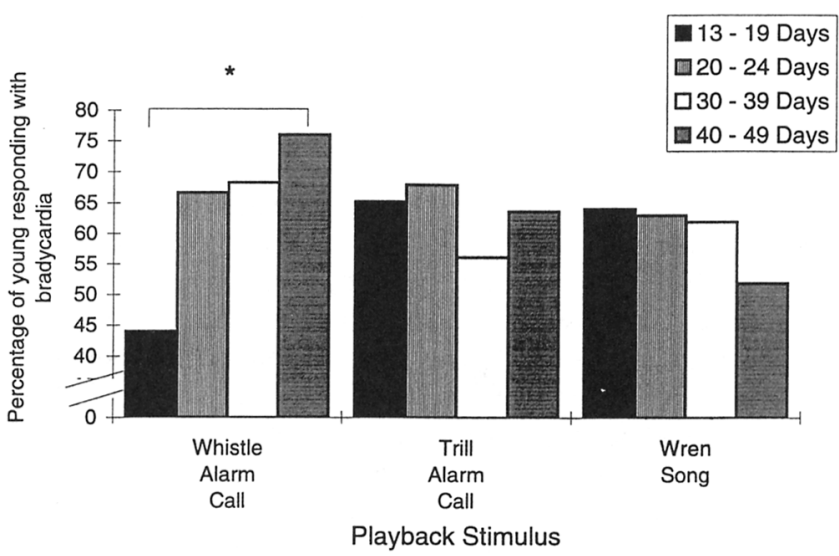

Figure 3. Proportion of all ground squirrels responding to each playback stimulus with decreased heart rates (bradycardia) in each age cohort. Responses of the loud and quiet groups were pooled within each age cohort (see Table 1 for sample sizes). The bracket represents a significant $(p<.05)$ difference between $13-19$ and $40-49$ days of age (see text for details). with tachycardia to wren songs as compared with chance, but not significantly so $(p=.08)$. No other trends were found in the responses to wren song stimuli and either whistle or trill stimuli.

\section{Discussion}

Belding's ground squirrels exhibited a pattern of differential cardiac responses to conspecific calls, such that animals more than 20 days old tended to respond with decreased heart rates to whistle alarm calls and with increased heart rates to trill playbacks. The results suggest that pups were able to discriminate between trills and whistles before the age when they first emerge above ground, although additional research would be necessary to determine why not all individuals responded differentially to the two calls. Whereas this trend approached statistical significance only in 30-49-day-old juveniles, the overall direction was similar across age cohorts (Figure 4). The lack of a clear heart-rate difference in the older cohorts may be attributed to developmental changes in ground squirrel cardiovascular systems (Haroutunian \& Campbell, 1981; Richardson et al., 1992). Note, however, that when the heart-rate patterns failed to reach statistical significance, juveniles were 1-3 weeks past the age of natal emergence and, if free living, would be exhibiting behavioral responses to the alarm calls. Moreover, by the normal age of natal emergence, heart-rate responses to the playback stimuli were significantly different (see Figure 4, 20-24-day-old cohort). This suggests that $S$. belding $i$ exhibit a preparedness at natal emergence enabling them to auditorily discriminate between the two conspecific alarm calls, whistles and trills, that are typically associated with aerial and terrestrial predators, respectively.

It is unclear why there were no significant differences in responses to wren songs and alarm calls. Nevertheless, there was a tendency for wren song playbacks to elicit tachycardia and for whistles to evoke bradycardia, particularly in older juveniles (40-49 days old). Ground squirrels may have been beginning to discriminate between these two stimuli but had more difficulty distinguishing trills from wren songs because these two calls were similar in duration 

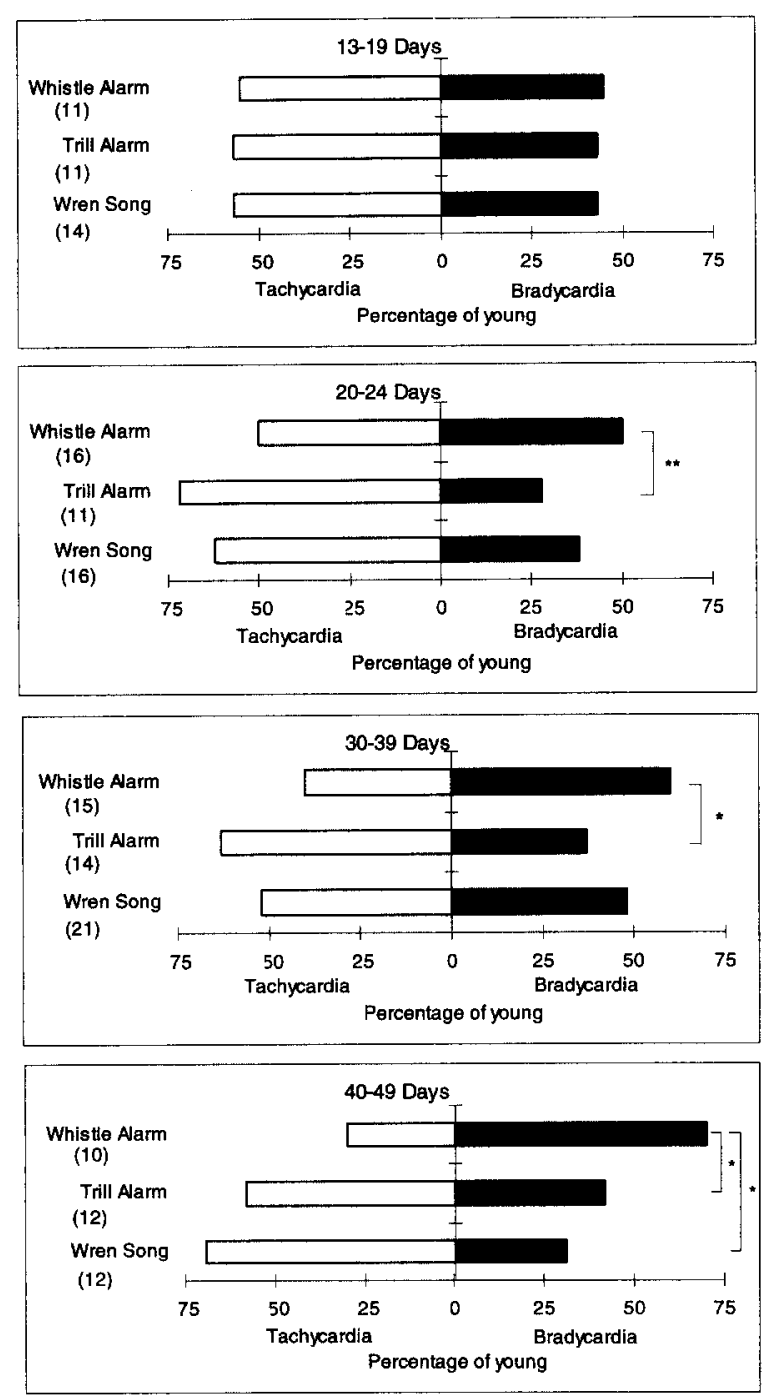

Figure 4. Percentage of animals responding with either tachycardia (open bars) or bradycardia (solid bars) to each playback stimulus in the four age cohorts. Bars total to $100 \%$ for each playback stimulus in each cohort. Responses of the loud and quiet groups were pooled within each cohort. Numbers in parentheses represent the total number of young exhibiting increased or decreased heart rates after that playback stimulus. Brackets represent significant differences $\left({ }^{*} p<.10,{ }^{* *} p<.05\right)$ in the direction of heart-rate responses to stimuli based on McNemar's change tests (see text for details).

and in number of syllables (Figure 1). Alternatively, both stimulus-evoked movements of animals (Berntson et al., 1992) and age-related changes in cardiac physiology (e.g., Haroutunian \& Campbell, 1981) could have resulted in large interindividual differences in the direction of responses, thus obscuring differentiation of the three stimuli. Alarm calls may have more stimulus value (Kruijt, 1985) than wren songs, and therefore ground squirrels may be able to discriminate between the conspecific calls with little experience, whereas recognition of heterospecific calls and discrimination of these calls from conspecific calls would develop later with extended exposure. Discrimination of the alarm calls is probably facilitated by the distinct acoustic characteristics of the calls (Klump \& Shalter, 1984; Marler, 1955; Rydén, 1978); whistles are higher in frequency and more tonal than trills, which in turn contain repeated notes (Figure 1; Leger et al., 1984; Robinson, 1980).

In ground squirrels more than 20 days of age, whistles tended to result in bradycardia rather than the tachycardia typical of defensive or startle reactions. There are three possible explanations for this. First, aversive stimuli, including alarm calls and the audiotactile stimuli I used (see Method section), can elicit bradycardia rather than tachycardia under some circumstances (Berntson et al., 1989; Espmark \& Langvatn, 1979; Gabrielsen et al., 1985; Jacobsen, 1979; Ruff, 1971; Smith \& Woodruff, 1980). Second, pre-emergent ground squirrels probably have not formed an association between whistles and fearful situations such as the approach of predators (see later discussion). Therefore, pups may not yet perceive the signal as threatening or potentially injurious and thus would not be expected to respond with defensive or startle responses. Third, bradycardia is associated with decreased motor activity (e.g., Berntson et al., 1992; Martin \& Alberts, 1982) and enhanced information processing (Richardson et al., 1992). During their first few days above ground, free-living juveniles often freeze after hearing an alarm call and are more likely to freeze after single whistles than after trills (Mateo, in press). I have proposed that, by freezing, juveniles can remain above ground after an alarm call and observe the responses of experienced conspecifics to the call. The discrimination of alarm calls from nonalarm calls may be contingent on this freezing; juveniles learn through habituation that harmless stimuli are not associated with danger or take cues from adults as to which signals are important (see also Cheney \& Seyfarth, 1990). Whistles may elicit bradycardia (and its subsequent somatic inhibition and perceptual focusing) more often than trills because whistles are associated with fast-moving predators and thus require more attention than trills, which warn of slow-moving predators (Sherman, 1976, 1985). In free-living juveniles, age-appropriate behavioral responses to whistles develop before responses to trills (Mateo, in press).

Differences in the early auditory experiences of ground squirrels in the quiet and loud groups did not significantly affect heart-rate responses to playbacks. Nelson and Marler (1993) concluded that innate auditory templates were responsible for selective learning of conspecific vocalizations by hand-reared white-crowned sparrows (Zonotrichia leucophrys nuttalli). Note that although pre-emergent ground squirrels in the present study also exhibited selective responses to conspecific calls, the auditory stimulation they experienced during very early development could have contributed to these discriminative abilities. Whereas variation in the amount of stimulation had no discernible effect (as shown earlier), early exposure to $S$. beldingi calls may influence discrimination. The quiet group was composed of 3 dams and their litters, so the frequency of auditory stimulation was still higher than what pups, as isolated litters, 
normally experience in the field. Alternatively, the development of discrimination may be facilitated by postemergent, but not pre-emergent, exposure to alarm calls. My data do not permit elimination of either possibility. However, baseline heart rates differed between the two rearing conditions from 13 to 39 days of age (Figure 2). As a result of their rearing environment, the loud-group animals may have been more aroused by the testing situation than the quiet-group animals, resulting in increased baseline heart rates (Richardson, Siegel, \& Campbell, 1988a, 1988b). Furthermore, studies of behavioral responses to alarm-call playbacks have implicated pre-emergent histories in the postemergent response differences between captive and free-living juveniles (Mateo, 1995).

Although the data suggest that newly emergent juveniles can discriminate between conspecific trills and whistles, their behavioral responses to these calls are not predictable (Mateo, in press). In young ground squirrels, trills and whistles evoke different internal states and, thus, different cardiac responses. However, these states do not inevitably lead to distinct behavioral reactions as they might in older ground squirrels. Plasticity in responses during the first few days above ground may be advantageous for young $S$. beldingi. During ground squirrel phylogeny, it is unlikely that there was sufficient selection pressure on peri-emergent ground squirrels to form associations between alarm calls and specific escape responses (but see Coss, 1991). The likelihood of an individual pup in its natal burrow or a newly emergent juvenile encountering a predator was probably small; if it had been attacked, however, it would have been very unlikely to survive. "Successful" responses would have been uncommon and, therefore, unlikely to be strongly selected. As a result, extant ground squirrels do not behave differentially to calls when they first emerge above ground.

During their first few days above ground, juveniles quickly develop an association between alarm calls and adaptive behavioral responses, in part by remaining above ground after hearing a call and "observing" how other squirrels (potentially dams) react (see Mateo, in press). This process would be facilitated by auditory discrimination that prompts juveniles to attend to conspecific calls. Such a plastic developmental system would be beneficial if the predator context varied either spatially or temporally (e.g., Coss \& Owings, 1985) or if the prey species were found in habitats differing in visibility or refuges (see Armitage, 1982). Hence, the development of discriminative behavioral responses to various auditory stimuli is the result of opportunities to hear alarm calls before emerging above ground, of hearing and responding to calls after emergence, and of observing the reactions of conspecifics to the same calls (Mateo, in press; see also Cheney \& Seyfarth, 1990). Young therefore first learn differences among auditory signals, then learn which signals to respond to and which to disregard, and finally, develop behavioral responses appropriate to each stimulus. As this development continues, juveniles also learn context-dependent differences in conspecific calls, such as predator-elicited versus conspecific-elicited trills (Robinson, 1981) or variations in calls specific to the local predator environment (e.g., Owings \& Leger, 1980).

Recall that unlike the direction of heart-rate responses, the magnitude of ground squirrels' responses failed to reveal discrimination as a function of the ages of the young or the environment in which they were reared. There are a number of possible explanations for this lack of differentiation. First, the stimulus durations (less than $2 \mathrm{~s}$ for trills and about $100 \mathrm{~ms}$ for whistles) may be have been too short to elicit differential magnitudes (cf. stimulus durations presented by Espmark \& Langvatn, 1979; Haroutunian \& Campbell, 1981; Jacobsen, 1979; Ruff, 1971). Second, the animals were tested in their familiar nest box, but the dam and siblings were absent. Unfamiliar testing environments are known to alter cardiac responses (Richardson et al., 1988a, 1988b). However, the baseline BPM of $S$. beldingi did not diminish, even after $30 \mathrm{~min}$, suggesting that the testing environment itself did not overstimulate the animals and thus restrict the range of heart-rate variability. Finally, it was necessary for me to loosely wrap animals in an ace bandage to protect both them and the copper-wire electrodes. Many of the studies reviewed earlier used either a radiotelemetric system or an apparatus specifically designed to minimize movement and keep the electrodes suspended. Note, however, that restricting motor movements may sometimes promote the expression of cardiac responses by eliminating cardiosomatic coupling (Berntson et al., 1992; Martin \& Alberts, 1982; Richardson et al., 1992).

The magnitude of cardiac responses of young $S$. beldingi to potentially threatening situations contrasts with responses made by the young of other species, including ducklings (Anas platyrhynchos; Evans \& Gaoni, 1990) and infant chimpanzees (Pan troglodytes; Berntson \& Boysen, 1989). For example, the bradycardia exhibited by Belding's ground squirrels is much smaller than that exhibited by newborn ungulates (3\% and more than $30 \%$, respectively; Espmark \& Langvatn, 1979; Jacobsen, 1979). Perhaps a single presentation of an auditory stimulus (this study) is less immediately threatening than the lengthy visual and olfactory approach of a human or dog (Canis familiaris) that other investigators have used (Espmark \& Langvatn, 1979; Gabrielsen et al., 1985; Jacobsen, 1979; Ruff, 1971). Furthermore, newly emergent free-living $S$. belding $i$ are often exposed to more than a single emission of an alarm call. In the field, young may hear multiple alarm calls, see many adults responding by posting or running to a burrow, and even fall into their burrow when the dam runs to and enters it (personal observation).

In summary, $S$. beldingi pups respond to playbacks of conspecific and heterospecific vocalizations with small decreases in heart rates, typical of orienting responses. Moreover, the pattern of heart-rate responses by individual ground squirrels differentiates between trill and whistle alarm calls, suggesting that even before they emerge above ground young can discriminate between conspecific calls. This preparedness may facilitate the acquisition of adaptive behavioral responses to alarm calls by post-emergent young. 


\section{References}

Alberts, J. R. (1984). Sensory-perceptual development in the Norway rat: A view toward comparative studies. In R. V. Kail \& N. E. Spear (Eds.), Comparative perspective on the development of memory (pp. 65-101). Hillsdale, NJ: Erlbaum.

Armitage, K. B. (1982). Marmots and coyotes: Behavior of prey and predator. Journal of Mammalogy, 63, 503-505.

Berntson, G. G., \& Boysen, S. T. (1989). Specificity of the cardiac response to conspecific vocalizations in chimpanzees. Behavioral Neuroscience, 103, 235-245.

Berntson, G. G., Boysen, S. T., Bauer, H. R., \& Torello, M. S. (1989). Conspecific screams and laughter: Cardiac and behavioral reactions of infant chimpanzees. Developmental Psychobiology, 22, 771-787.

Berntson, G. G., Boysen, S. T., \& Cacioppo, J. T. (1992). Cardiac orienting and defensive responses: Potential origins in autonomic space. In B. A. Campbell, H. Hayne, \& R. Richardson (Eds.), Attention and information processing in infants and adults: Perspectives from human and animal research (pp. 163200). Hillsdale, NJ: Erlbaum.

Cheney, D. L., \& Seyfarth, R. M. (1990). How monkeys see the world. Chicago: University of Chicago Press.

Coss, R. G. (1991). Context and animal behavior III: The relationship between early development and evolutionary persistence of ground squirrel antisnake behavior. Ecological Psychology, 3, 277-315.

Coss, R. G., \& Owings, D. H. (1985). Restraints on ground squirrel antipredator behavior: Adjustments over multiple time scales. In T. D. Johnston \& A. T. Pietrewicz (Eds.), Issues in the ecological study of learning (pp. 167-200). Hillsdale, NJ: Erlbaum.

Dooling, R., \& Searcy, M. (1980). Early perceptual selectivity in the swamp sparrow. Developmental Psychobiology, 13, 499506.

Engineering Design. (1992). Signal Software [Computer software]. Belmont, MS: Author.

Espmark, Y., \& Langvatn, R. (1979). Cardiac responses in alarmed red deer calves. Behavioural Processes, 4, 179-186.

Evans, C. S., \& Gaoni, S. J. (1990). Conspecific calls evoke characteristic cardiac responses in mallard ducklings. Animal Behaviour, 39, 785-796.

Gabrielsen, G. W., Blix, A. S., \& Ursin, H. (1985). Orienting and freezing responses in incubating ptarmigan hens. Physiology and Behavior, 34, 925-934.

Gerhardt, H. C. (1992). Conducting playback experiments and interpreting their results. In P. K. McGregor (Ed.), Playback and studies of animal communication (pp. 59-77). New York: Plenum.

Gilman, A. G., Rall, T. W., Nies, A. S., \& Taylor, P. (1990). The pharmacological basis of therapeutics (8th ed.). New York: Pergamon Press.

Gottleib, G. (1971). Development of species identification in birds: An inquiry into the prenatal determinants of perception. Chicago: University of Chicago Press.

Haroutunian, V., \& Campbell, B. A. (1981). Development and habituation of the heart rate orienting response to auditory and visual stimuli in the rat. Journal of Comparative and Physiological Psychology, 95, 166-174.

Impekoven, M. (1976). Responses of laughing gull chicks (Larus atricilla) to parental attraction- and alarm-calls, and effects of prenatal auditory experience on the responsiveness to such calls. Behaviour, 56, 250-277.

Jacobsen, N. K. (1979). Alarm bradycardia in white-tailed deer fawns (Odocoileus virginianus). Journal of Mammalogy, 60, 343-349.

Jenkins, G. M., \& Watts, D. G. (1968). Spectral analysis and its applications. San Francisco: Holden-Day.

Klump, G. M., \& Shalter, M. D. (1984). Acoustic behaviour of birds and mammals in the predator context: I. Factors affecting the structure of alarm signals. Zeitschrift fur Tierpsychologie, $66,189-226$.

Kroodsma, D. E. (1986). Design of song playback experiments. $A u k, 103,640-643$.

Kruijt, J. P. (1985). On the development of social attachments in birds. Netherlands Journal of Zoology, 35, 45-62.

Leger, D. W., Berney-Key, S. D., \& Sherman, P. W. (1984). Vocalizations of Belding's ground squirrels (Spermophilus beldingi). Animal Behaviour, 32, 753-764.

Lickliter, R., \& Stoumbos, J. (1991). Enhanced prenatal auditory experience facilitates species-specific visual responsiveness in bobwhite quail chicks (Colinus virginianus). Journal of Comparative Psychology, 105, 89-94.

Marler, P. (1955). Characteristics of some animal calls. Nature, $176,6-8$.

Martin, L. T., \& Alberts, J. R. (1982). Associative learning in neonatal rats revealed by cardiac response patterns. Journal of Comparative and Physiological Psychology, 96, 668-675.

Mateo, J. M. (1995). The development of alarm-call responses in free-living and captive Belding's ground squirrels, Spermophilus beldingi. Unpublished doctoral dissertation, University of Michigan, Ann Arbor.

Mateo, J. M. (in press). The development of alarm-call response behaviour in free-living juvenile Belding's ground squirrels. Animal Behaviour.

Murie, J. O., \& Boag, D. A. (1984). The relationship of body weight to overwinter survival in Columbian ground squirrels. Journal of Mammalogy, 65, 688-690.

Nelson, D. A., \& Marler, P. (1993). Innate recognition of song in white-crowned sparrows: A role in selective vocal learning? Animal Behaviour, 46, 806-808.

Owings, D. H., \& Leger, D. W. (1980). Chatter vocalizations of California ground squirrels: Predator- and social-role specificity. Zeitschrift fur Tierpsychologie, 54, 163-184.

Richardson, R., Hayne, H., \& Campbell, B. A. (1992). The orienting response as a measure of attention and information processing in the developing rat. In B. A. Campbell, H. Hayne, \& R. Richardson (Eds.), Attention and information processing in infants and adults: Perspectives from human and animal research (pp. 113-136). Hillsdale, NJ: Erlbaum.

Richardson, R., Siegel, M. A., \& Campbell, B. A. (1988a). Effect of maternal presence on the fear response to an unfamiliar environment as measured by heart rate in rats as a function of age. Developmental Psychobiology, 21, 613-633.

Richardson, R., Siegel, M. A., \& Campbell, B. A. (1988b). Unfamiliar environments impair information processing as measured by behavioral and cardiac orienting responses to auditory stimuli in preweanling rats. Developmental Psychobiology, 21, 491503.

Robinson, S. R. (1980). Antipredator behaviour and predator recognition in Belding's ground squirrels. Animal Behaviour, 28, $840-852$.

Robinson, S. R. (1981). Alarm communication in Belding's ground squirrels. Zeitschrift fur Tierpsychologie, 56, 150-168.

Ruff, R. L. (1971). Telemetered heart rates of free-living Uinta ground squirrels in response to social interactions. Unpublished doctoral dissertation, Utah State University, Logan.

Rydén, O. O. (1978). Differential responsiveness of great tit nest- 
lings, Parus major, to natural auditory stimuli: Response strength as related to stimulus significance and previous individual experience. Zeitschrift fur Tierpsychologie, 47, 236-253.

Sherman, P. W. (1976). Natural selection among some groupliving organisms. Unpublished doctoral dissertation, University of Michigan, Ann Arbor.

Sherman, P. W. (1985). Alarm calls of Belding's ground squirrels to aerial predators: Nepotism or self-preservation? Behavioral Ecology and Sociobiology, 17, 313-323.

Sherman, P. W., \& Morton, M. L. (1984). Demography of Belding's ground squirrels. Ecology, 65, 1617-1628.

Siegel, S., \& Castellan, N. J. (1988). Nonparametric statistics for the behavioral sciences. New York: McGraw-Hill.

Smith, E. N., \& Woodruff, R. A. (1980). Fear bradycardia in free-ranging woodchucks, Marmota monax. Journal of Mammalogy, 61, 750-753.

Thomas, D. A., Talalas, L., \& Barfield, R. J. (1981). Effects of devocalization of the male on mating behavior in rats. Journal of Comparative and Physiological Psychology, 95, 630-637.

Vince, M. A. (1980). The posthatching consequences of prehatching stimulation: Changes with amount of prehatching and posthatching exposure. Behaviour, 75, 36-53.

Received June 9, 1995

Revision received September 5, 1995

Accepted September 28, 1995

\section{Research Awards in Comparative and Physiological Psychology}

The Division of Comparative and Physiological Psychology of the American Psychological Association (Division 6) announces its first annual research awards. These awards are based on review of the research published in Behavioral Neuroscience and the Journal of Comparative Psychology in the past year. The intention is to provide early recognition to scholars whose research contributions are especially promising and of high quality. The awards for 1995 are as follows:

\section{Behavioral Neuroscience}

Winner

Robert J. McDonald and Norman M. White, McGill University

"Hippocampal and Nonhippocampal Contributions to Place Learning in Rats"

\section{Honorable Mention}

Ludiše Málková, Mortimer Mishkin, and Jocelyne Bachevalier, National Institute of Mental Health "Long-Term Effects of Selective Neonatal Temporal Lobe Lesions on Learning and Memory in Monkeys"

\section{Journal of Comparative Psychology}

\section{Winner}

Todd M. Freeberg, Andrew P. King, and Meredith J. West, Indiana University

"Social Malleability in Cowbirds (Molothrus ater artemisiae): Species and Mate Recognition in the First 2 Years of Life"

\section{Honorable Mention}

Juan D. Delius and Valerie D. Hollard, Universität Konstanz, Konstanz, Germany

"Orientation Invariant Pattern Recognition by Pigeons (Columbia livia) and Humans (Homo sapiens)"

These awards will be presented at the APA annual convention. 